\title{
Human outer dense fiber gene, ODF2, localizes to chromosome 9q34
}

\author{
X. Shao, ${ }^{a}$ S. Murthy, ${ }^{a, b}$ D.J. Demetrick ${ }^{a, b}$ and F.A. van der Hoorn ${ }^{a}$ \\ a Department of Biochemistry and Molecular Biology, and \\ ${ }^{b}$ Department of Pathology, University of Calgary, Calgary, Alberta (Canada)
}

Abstract. We have isolated the human homolog of the rat Odf2 gene. In rat, Odf2, the $84-\mathrm{kDa}$ major outer dense fiber protein, interacts strongly and specifically with Odf1, the 27$\mathrm{kDa}$ major outer dense fiber protein. The interaction is mediated by leucine zippers during ODF assembly along the sperm axoneme. We compared homology and genomic structure to rat and mouse Odf2 genes. Using fluorescence in situ hybridization, we mapped the human Odf2 gene (ODF2) to chromosome 9q34.
The mammalian spermatozoon contains characteristic cytoskeletal structures associated with the central axoneme: nine outer dense fibers (ODF) extend taperingly throughout the midpiece and terminate in the principal piece while the fibrous sheath $(\mathrm{FS})$ replaces two of the ODF and surrounds the remaining ODF in the principal piece (Fawcett, 1975). The polypeptide composition of ODF in rats has been known to contain six major polypeptides as well as several minor polypeptides, many of which are highly insoluble (Olson and Sammons, 1980; Vera et al., 1984; Oko and Clermont, 1988). These proteins are produced exclusively in spermatids and assembled in a proximal-to-distal manner along the axoneme (Oko and Clermont, 1989). The structural integrity of ODF as well as the FS is believed to be associated with sperm motility and male fertility. However, little is known about the relationship between the genetic defects of the ODF genes and abnormal ODF morphogenesis underlying human male infertility. This is largely due to the uncharacterized biochemical properties of the individual

Supported by grants to F.A.v.d.H. from the Medical Research Council of Canada and to D.J.D. from the Canadian Breast Cancer Research Initiative. X.S. was supported by a studentship from the Alberta Heritage Foundation for Medical Research. D.J.D. is a Medical Research Council of Canada Clinician-scientist.

Received 9 October 1998; manuscript accepted 18 November 1998

Request reprints from Dr. Frans A. van der Hoorn, Department of Biochemistry and Molecular Biology, University of Calgary Health Sciences Center,

3330 Hospital Drive N.W., Calgary, Alberta, T2N 4NI (Canada);

telephone: 403-220-3323; fax: 403-283-8727; e-mail: fvdhoorn@ucalgary.ca
ODF components. Until recently only one ODF gene, ODF1, which encodes the major 27-kDa ODF protein, had been cloned (van der Hoorn et al., 1990; Burfeind and Hoyer-Fender, 1991; Morales et al., 1994). Human ODF1 localizes to chromosome 8q22 (Gastmann et al., 1993).

Recently, we cloned several testis-specific proteins which interact strongly and specifically with Odf1 by using the $\mathrm{N}$ terminus of Odf1, which includes the leucine zipper motif (Shao and van der Hoorn, 1996), as a bait in a yeast genetic screen (Shao et al., 1997). One of the novel genes characterized encodes the major 84-kDa ODF protein, Odf2 (previously called Odf84) (Shao et al., 1997). We determined that a second novel gene, SPAG4, encoding a spermatid-specific protein, which also interacts strongly with Odf1 (Shao et al., manuscript in preparation), localizes to human chromosome 20q11.2 (Tarnasky et al., 1998). In the present study, we isolated a human genomic clone of Odf2 2 and used it as a probe to map human ODF2 to chromosome 9q34 by fluorescence in situ hybridization (FISH).

\section{Materials and methods}

Isolation of human ODF2

To isolate human genomic clones of ODF2, the rat Odf2 cDNA was used as a probe to screen a human genomic library (Stratagene), of which the DNA was prepared from Caucasian male placenta and cloned into the $\mathrm{XhoI}$ site of lambda FIX_II vector under stringent conditions. Insert sizes range from 9 to $22 \mathrm{~kb}$. Approximately $1 \times 10^{6} \mathrm{pfu}$ were screened and three positive genomic clones were isolated using standard techniques (Sambrook et al., 1989). The

\begin{tabular}{lll}
\hline KARGER & $\begin{array}{l}\text { E-mail karger@karger.ch } \\
\text { Fax +41 61306 12 34 } \\
\text { http://www. karger.com }\end{array}$ & (c) 1997 S. Karger AG, Basel \\
$0301-0171 / 98 / 0834-0221 \$ 17.50 / 0$
\end{tabular}

Accessible online at:

http://BioMedNet.com/karger 
3'splice site

human ODF2 gene

rat Odf2 cDNA

GCAAAGAG | GATTCCGAGAGACTAATGGAGCAACAAGGTGCATT

human ODF2 gene

rat Odf2 cDNA

ACTGAAACGTCTGGCAGAGGCCGACTCAGAGAAAGCG | CGCCTG

5 'splice site

Fig. 1. Nucleotide sequence of a human ODF2 exon. The nucleotide sequence of one exon of human ODF2 is compared to the corresponding rat Odf 2 cDNA sequence. The $5^{\prime}$ and $3^{\prime}$ exon-intron boundaries are indicated.

genomic DNA was isolated from these clones individually and characterized by restriction mapping and Southern blot hybridization and selected fragments that hybridized to rat $O d f 2$ cDNA probes were sequenced to define exon-intron boundaries.

\section{Fluorescence in situ hybridization}

FISH was performed using previously established methods on methotrexate-thymidine synchronized, phytohemagglutinin stimulated, normal peripheral blood lymphocytes (Demetrick, 1995). Suppression for $30 \mathrm{~min}$ with a mixture of sonicated human DNA (Sigma) and cot-1 DNA (Gibco/BRL) was required to reduce the background. The stained slides were counterstained with DAPI and actinomycin D (for a DA-DAPI banding pattern) and were mounted in antifade medium and visualized utilizing a Zeiss Axioplan 2 microscope. Approximately 30 metaphase spreads were examined for probe location. Images of representative mitoses were captured using a cooled CCD camera (Photometrics PXL1400). Digital alignment of the images from each fluor was done after registration calibration through a triple bandpass filter (FITC/Texas Red/DAPI) to minimize registration error, utilizing commercial software (Electronic Photography v 1.3, Biological Detection Inc., Pittsburgh PA).

\section{Results and discussion}

Human genomic clones were isolated from a lambda FIX_II human genomic library using rat $O d f 2$ cDNA as a probe. Genomic DNA prepared from each positive clone was analyzed by restriction mapping and Southern blot hybridization. One of these clones, called hg $\lambda 1$, was further analyzed. A $1.3-\mathrm{kb}$ PstI fragment of hg $\lambda 1$ DNA, which can be hybridized to rat Odf 2 cDNA, was subcloned and sequenced to determine the exon-intron boundaries. Figure 1 shows the sequence of the exon and exon-intron boundaries in comparison to the corresponding rat $O d f 2$ cDNA sequence. The human and rat Odf2 exons are $90 \%$ identical at the nucleotide level and the amino acid sequence encoded by this exon is $100 \%$ identical. The $5^{\prime}$ and $3^{\prime}$ splice junction sequences of the human ODF2 clone match $5^{\prime}$ and $3^{\prime}$ splice site consensus sequences. Interestingly, the genomic organization of this exon is identical to that of the mouse gene (Shao and van der Hoorn, unpublished data), indicating evolutionary conservation of the genomic organization of this exon between mouse, rat and human.

To determine the chromosome location of ODF2, a 20-kb insert of human genomic clone hg $\lambda 1$ was labeled with digoxigenin-dUTP and hybridized to synchronized human lymphocyte metaphase spreads as detailed above (Fig. 2). These results

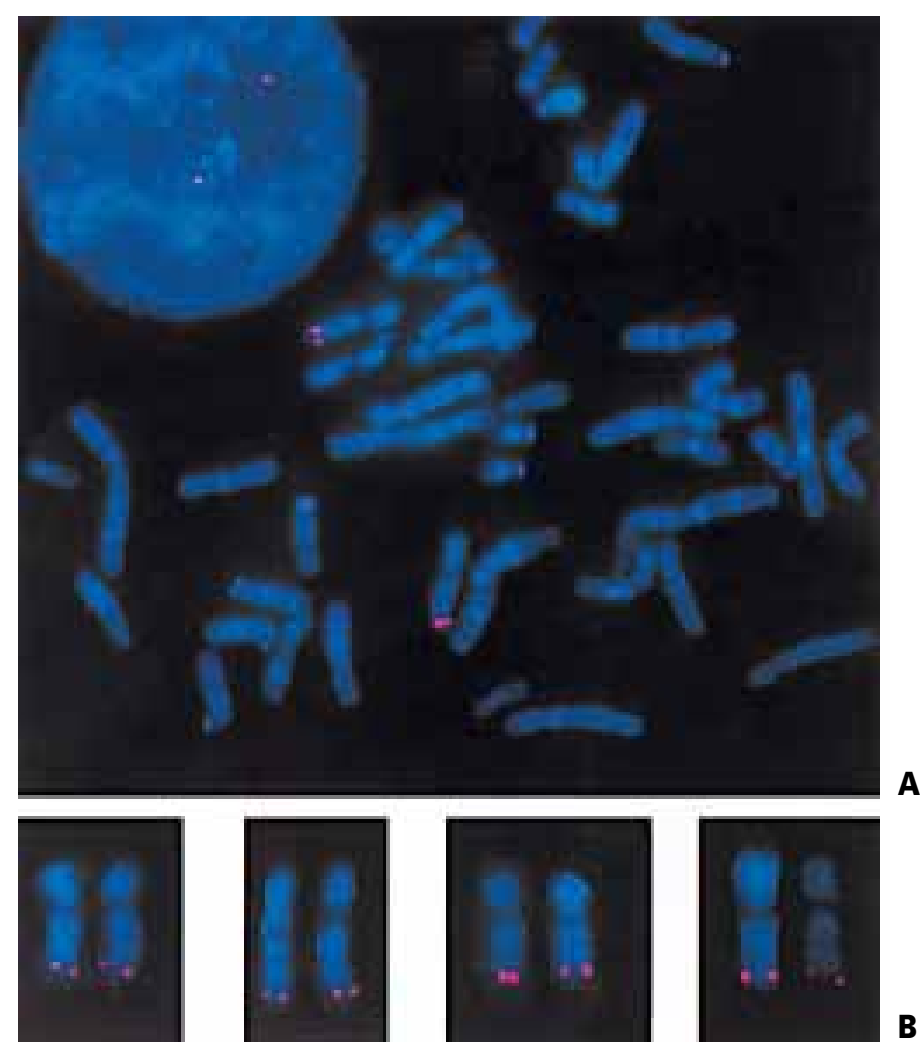

Fig. 2. Localization of ODF2 on human metaphase chromosomes. (A) Metaphase spread with specific dual-chromatid staining of a Cy3-labeled genomic ODF2 probe (red) to 9q34 on DAPI/AD (white-blue) stained normal human chromosomes. (B) Several enlarged pairs of chromosome 9 from different metaphases showing consistent localization of the ODF2 probe (red) to normal DAPI/AD stained human chromosomes.

clearly show localization of the probe to $9 \mathrm{q} 34$. At least one specific probe signal was present in more than $90 \%$ of the mitoses examined. Approximately $80 \%$ of the spreads showed labeling of two chromatids of a single chromosome and more than half of these showed specific labeling of both chromatids of both chromosomes. More than $90 \%$ of these signals were localized to a single band, $9 \mathrm{q} 34$.

The location of ODF2 on human chromosome 9q34, to which area a number of genes have been mapped, is not linked to any known testis-specific gene. Human ODF1 has been localized to chromosome 8q22 (Gastmann et al., 1993), we recently mapped SPAG4, encoding an Odf1 interacting protein (Shao et al., manuscript in preparation), to human chromosome 20q11.2 (Tarnasky et al., 1998) and acrosin, an acrosomal protease, was localized to $22 \mathrm{q} 13 \rightarrow$ qter (Vazquez-Levin et al., 1992). It appears that genes which function in spermiogenesis are dispersed throughout the genome. Odf2, which has two leucine zippers, interacts strongly and specifically with Odf1 via its upstream leucine zipper during ODF assembly in elongating spermatids, and the second leucine zipper may interact with other ODF or sperm tail structural proteins (Shao et al., 1997). Thus Odf2 protein is probably a crucial player in the organiza- 
tion of ODF morphogenesis. Interestingly, we recently demonstrated that Odf2 protein is also detectable in the sperm connecting piece (Schalles et al., 1998), a structure derived from the centriole which is involved in aster formation after fertilization of the egg (Long et al., 1997). Our observations are directly relevant to the investigation of human male infertility. Male infertility contributes to $50 \%$ of couples unable to conceive children: sperm structural abnormalities are a large fraction of these cases, but so far cytogenetic analyses of infertile males can only detect gross chromosome abnormalities (Yoshida et al., 1997). Therefore, the chromosomal localization of ODF2 in conjunction with antisera that we raised against Odf1, Odf2 and Spag4 proteins will allow us to investigate and diagnose human male infertility syndromes, which are a consequence of genetic defects in the ODF1, SPAG4 and ODF2 genes. The phenotype associated with such genetic defects likely includes abnormal sperm tail function and/or motility, as well as inability to fertilize eggs.

\section{Acknowledgements}

We thank the Faculty of Medicine, University of Calgary for an Establishment Grant for the FISH equipment.

\section{References}

Burfeind P, Hoyer-Fender S: Sequence and developmental expression of an mRNA encoding a putative protein of rat sperm outer dense fibers. Dev Biol 148:195-204 (1991).

Demetrick DJ: Fluorescence in situ hybridization and human cell cycle genes, in Pagano M (ed): The Cell Cycle - Materials and Methods, pp 29-45 (Springer, New York 1995).

Fawcett DW: The mammalian spermatozoon. Dev Biol 44:394-436 (1975).

Gastmann O, Burfeind P, Gunther E, Hameister H, Szpirer C, Hoyer-Fender S: Sequence, expression, and chromosomal assignment of a human sperm outer dense fiber gene. Mol Reprod Dev 36:407418 (1993).

Long CR, Duncan RP, Robl JM: Isolation and characterization of MPM-2-reactive sperm proteins: homology to components of the outer dense fibers and segmented columns. Biol Reprod 57:246-254 (1997).
Morales CR, Oko R, Clermont Y: Molecular cloning and developmental expression of an mRNA encoding the $27-\mathrm{kDa}$ outer dense fiber protein of rat spermatozoa. Mol Reprod Dev 37:229-240 (1994).

Oko R, Clermont Y: Isolation, structure and protein composition of the perforatorium of rat spermatozoa. Biol Reprod 39:673-687 (1988).

Oko R, Clermont Y: Light microscopic immunocytochemical study of fibrous sheath and outer dense fiber formation in the rat spermatid. Anat Rec 225:46-55 (1989).

Olson GE, Sammons DW: Structural chemistry of outer dense fibers of rat sperm flagellum. Biol Reprod 22:319-332 (1980).

Sambrook J, Fritsch EF, Maniatis T: Molecular cloning: a laboratory manual (Cold Spring Harbor Laboratory Press, Cold Spring Harbor 1989).

Schalles U, Shao X, van der Hoorn FA, Oko R: Developmental expression of the 84-kDa ODF sperm protein: localization to both the cortex and medulla of outer dense fibers and to the connecting piece. Dev Biol 199:250-260 (1998).

Shao X, van der Hoorn FA: Self-interaction of the major $27-\mathrm{kDa}$ outer dense fiber protein is in part mediated by a leucine zipper domain. Biol Reprod 55:1343-1350(1996).
Shao X, Tarnasky HA, Schalles U, Oko R, van der Hoorn FA: Leucine zippers mediate interactions of sperm tail-specific structural proteins. J biol Chem 272:6105-6113 (1997)

Tarnasky H, Gill D, Murthy S, Shao X, Demetrick DJ, van der Hoorn FA: A novel testis-specific gene, SPAG4, whose product interacts specifically with outer dense fiber protein ODF27, maps to human chromosome 20q11.2. Cytogenet Cell Genet 81:65-67 (1998).

van der Hoorn FA, Tarnasky HA, Nordeen SK: A new rat gene RT7 is specifically expressed during spermatogenesis. Dev Biol 142:147-154 (1990).

Vazquez-Levin MH, Reventos J, Gordon JW: Molecular cloning, sequencing and restriction mapping of the genomic sequence encoding human proacrosin. Eur J Biochem 190:195-200 (1992).

Vera JC, Brit M, Zuvic T, Burzio LO: Polypeptide composition of rat sperm outer dense fibers. $\mathrm{J}$ biol Chem 259:5970-5977 (1984).

Yoshida A, Miura K, Shirai M: Cytogenetic survey of 1,007 infertile males. Urol Int 58:166-176 (1997). 